\title{
Erratum to: Effects of aluminum exposure on the allergic responses and humoral immune function in rats
}

\author{
Yanzhu Zhu $\cdot$ Jinfeng Xu $\cdot$ Hao Sun $\cdot$ \\ Chongwei Hu • Hansong Zhao • Bing Shao • \\ Alphajoh A. Bah • Yanfei Li
}

Published online: 21 June 2011

(C) Springer Science+Business Media, LLC. 2011

\section{Erratum to: Biometals \\ DOI 10.1007/s10534-011-9443-4}

Regrettably, errors were introduced in Tables 2 and 3 of the above mentioned publication. The values of the standard deviation (SD) were not properly represented. The correct representation of Tables 2 and 3 is published below and should be treated as definitive by the reader.

Table 2 Concentrations $(\mathrm{mg} / \mathrm{ml})$ of $\mathrm{IgG}, \mathrm{IgM}, \mathrm{IgA}$, and $\mathrm{IgE}$ in serum of rats (mean $\pm \mathrm{SD}, n=10$ per group)

\begin{tabular}{lllll}
\hline & IgG & IgA & IgM & IgE \\
\hline GC & $0.21 \pm 0.0119$ & $0.022 \pm 0.0025$ & $0.034 \pm 0.0025$ & $0.0025 \pm 0.00057$ \\
GL & $0.22 \pm 0.0183$ & $0.037 \pm 0.0036^{*}$ & $0.023 \pm 0.0036^{*}$ & $0.0029 \pm 0.00053$ \\
GM & $0.24 \pm 0.0146$ & $0.03 \pm 0.0008^{* *}$ & $0.022 \pm 0.0008^{* *}$ & $0.0044 \pm 0.00022^{* *}$ \\
GH & $0.31 \pm 0.0047 * *$ & $0.061 \pm 0.0030^{* *}$ & $0.018 \pm 0.0030^{* *}$ & $0.0056 \pm 0.00031^{* *}$ \\
\hline
\end{tabular}

$G C$ control group; $G L$ low-dose group; $G M$ medium-dose group; $G H$ high-dose group

$* P<0.0005, * * P<0.0001$ versus control group

The online version of the original article can be found under doi:10.1007/s10534-011-9443-4.

Y. Zhu $\cdot$ H. Sun $\cdot$ C. Hu $\cdot$ H. Zhao $\cdot$ B. Shao.

A. A. Bah · Y. Li $(\square)$

College of Veterinary Medicine, Northeast Agricultural

University, Harbin 150030, China

e-mail: yanfeili200@yahoo.com.cn

J. Xu

College of Animal Sciences and Technology,

Heilongjiang Bayi Agricultural University, Daqing

163319, China
Table 3 Concentrations $(\mathrm{mg} / \mathrm{ml})$ of $\mathrm{C} 3$ and $\mathrm{C} 4$ in serum of rats (mean $\pm \mathrm{SD}, n=10$ per group)

\begin{tabular}{llc}
\hline & C3 & C4 \\
\hline GC & $0.59 \pm 0.00057$ & $0.05 \pm 0.00028$ \\
GL & $0.55 \pm 0.0151$ & $0.043 \pm 0.00071^{*}$ \\
GM & $0.51 \pm 0.0124 * *$ & $0.036 \pm 0.00014 * *$ \\
GH & $0.50 \pm 0.0035^{* *}$ & $0.033 \pm 0.0030^{* *}$ \\
\hline
\end{tabular}

$G C$ control group; $G L$ low-dose group; $G M$ medium-dose group; $G H$ high-dose group

$* P<0.0005$, ** $P<0.0001$ versus control group 